\title{
Radical Scavenging Capacity and Antioxidant Activity of the Vitamin E Extracted from Palm Fatty Acid Distillate by Sequential Cooling Hexane
}

\author{
Ronnakorn Sroynak $^{1,2}$, Pramoun Srikalong ${ }^{3} \&$ Patcharin Raviyan $^{1}$ \\ ${ }^{1}$ Division of Food Science and Technology, Faculty of Agro-Industry, Chiang Mai University, Chiang Mai, \\ Thailand \\ ${ }^{2}$ Division of Food Science and Technology, School of Agriculture and Natural Resources, University of Phayao, \\ Phayao, Thailand \\ ${ }^{3}$ Department of Food Process Engineering, Faculty of Agro Industry, King Mongkut's Institute of Technology \\ Ladkrabang, Bangkok, Thailand \\ Correspondence: Patcharin Raviyan, Division of Food Science and Technology, Faculty of Agro-Industry, \\ Chiang Mai University, Chiang Mai, Thailand. Tel: 66-8-9956-1078. E-mail: patraviyan@gmail.com
}

Received: January 28, 2012 Accepted: February 28, 2013 Online Published: March 20, 2013

doi:10.5539/jas.v5n4p224 URL: http://dx.doi.org/10.5539/jas.v5n4p224

\begin{abstract}
The radical scavenging capacity and antioxidant activity of the vitamin E extracted from palm fatty acid distillate by the sequential cooling hexane were compared to those of the synthetic antioxidants including butylated hydroxyanisole (BHA), 2,6-di-tert-butyl-4-methylphenol (BHT), pyrogallol (PG), tert-butylhydroquinone (TBHQ) and commercial $\alpha$-tocopherol. The extracted vitamin E contained 2,509.57, 9.24, 157.85, 6.70, 1,779.92, 3.97, $2,376.38,818.80$ and $7,662.45 \mathrm{ppm}$ of $\alpha-, \beta-, \gamma-, \delta$ - tocopherol and $\alpha-, \beta-, \gamma-, \delta$ - tocotrienol, and total vitamin $\mathrm{E}$, respectively. The maximum 2,2-diphenyl-1-picrylhydrazyl (DPPH) scavenging capacity of $20 \mathrm{ppm}$ extracted vitamin $\mathrm{E}$ was $89 \%$. The antioxidant activity determined by the methods of reducing power and ferric thiocyanate indicated that the $2.5 \mathrm{ppm}$ extracted vitamin E could inhibit the oxidation of linoleic acid emulsion for more than $80 \%$ within 1 day. The superoxide scavenging activity of the extracted vitamin $\mathrm{E}$ was greater than those of the BHT, commercial $\alpha$-tocopherol, and PG, respectively. The antioxidant activity of the extracted vitamin E was $91 \%$ which was similar to those of the BHT and synthetic $\alpha$-tocopherol. The total-vitamin E remained $73 \%$ after heating at $190^{\circ} \mathrm{C}$ for $3 \mathrm{~h}$. The tocopherol derivatives were more heat-stable than the tocotrienol derivatives while $\gamma$-tocopherol was the most heat-stable derivative. The concentration of total-vitamin $\mathrm{E}$ stored at $30^{\circ} \mathrm{C}$ for 120 days remained about $87 \%$ while the concentrations of vitamin $\mathrm{E}$ derivatives reduced by $2-20 \%$.
\end{abstract}

Keywords: vitamin E, extraction, palm fatty acid distillate, scavenging capacity, antioxidant activity

\section{Introduction}

Several studies have shown that vitamin E exhibits various beneficial properties including antioxidant and anticancer properties (Jung \& Min, 1990; Knekt et al., 1992; Maydani, 1995; Evans et al., 2002; Rossi et al., 2007). It performs most actively in scavenging free radicals and possesses the property of antioxidant which is effective in inhibiting free radicals in fat and fatty foods. Vitamin $\mathrm{E}$ is also able to reduce blood pressure and blood cholesterol, and prevent skin aging (Qureshi et al., 1988, 1991, 1996; Nesaretnam et al., 2007). Due to its numerous health related properties, vitamin $\mathrm{E}$ has been widely used in the manufacture of many health supplements, pharmaceutical products and cosmetics. In addition, vitamin $\mathrm{E}$ is widely used in animal feeds due to its antisterility properties (Eitenmiller \& Landen, 1999; Gianello et al., 2005; Senevirathne et al., 2006). With the increasing demand for vitamin $\mathrm{E}$, there is a pressing need to develop an efficient method, technique or process to produce sufficient quantities to meet the demand of the market.

Palm fatty acid distillate (PFAD) has been one of the interesting sources for natural vitamin E extraction (Goh et al., 1985; Sanagi et al., 2005). The PFAD is a by-product generated from the combination of high temperature heating approximately about $240-260^{\circ} \mathrm{C}$, under vacuum of $2.66-6.66 \mathrm{mbar}$ and direct steam injection of about $2.5 \%-4.0 \%$ by weight of oil at the deacidification-deodorization stage to remove the free fatty acids and odor in palm oil refining process (Leong, 1992). The distillate consists of $81.7 \%$ of free fatty acid, $14.4 \%$ of triglycerides, $0.8 \%$ of 
squalene, $0.5 \%$ of vitamin E, $2.2 \%$ of sterol and others (Gapor et al., 2002). $\mathrm{Ng}$ et al. (2004) reported that distillate contains $3,889.2 \pm 165.3 \mathrm{ppm}$ of vitamin E, comprising $79.5 \%$ of tocotrienols and $20.4 \%$ of tocopherols. The dominant component of tocopherol and tocotrienol in distillate are $\alpha$-tocopherol and $\gamma$-tocotrienol, respectively, while $\delta$-tocopherol and $\beta$-tocotrienol are not found in distillate ( $\mathrm{Ng}$ et al., 2004). However, Chu et al. (2003) reported that vitamin $\mathrm{E}$ in distillate is composed by $21.1,21.2,16.7$ and $41.0 \%$ of $\alpha$-tocopherol, $\alpha$-tocotrienol, $\delta$-tocotrienol and $\gamma$-tocotrienol, respectively. Purified palm oil contains total vitamin E at approximately 378-890 ppm (Top, 1990). Therefore, the main source of vitamin E is not the vegetable oil itself, but its distillate, a by-product from oil deodorization process (Hunt et al., 2000).

This study was conducted to compare the scavenging and antioxidant activities of vitamin E extracted from the PFAD by using the sequential cooling hexane with those of the synthetic antioxidants including BHA, BHT, PG, TBHQ and synthetic $\alpha$-tocopherol. Heat and storage stabilities of the vitamin E derivatives were also investigated.

\section{Materials and Methods}

\subsection{Materials}

The PFAD samples produced on the same production batch were provided by the Chumporn Palm Oil Industry Public Company Limited, Chumporn province, Thailand. The samples were kept in the closed containers at $30 \pm 5^{\circ} \mathrm{C}$ and used within 2 months. The BHA, BHT, PG, TBHQ and DPPH were purchased from the Sigma-aldrich. The other chemicals and reagents used for analysis were of analytical reagent grade.

\subsection{Extraction of Vitamin E from the PFAD by the Sequential Cooling Hexane}

The extraction of vitamin $E$ was operated under the optimal condition by mixing the melted PFAD sample with the hexane at the ratio of $1: 4(\mathrm{w} / \mathrm{v})$ and reducing temperature of the mixture sequentially to a series of pre-determined temperatures including $20^{\circ} \mathrm{C}, 15^{\circ} \mathrm{C}, 10^{\circ} \mathrm{C}, 5^{\circ} \mathrm{C}, 0^{\circ} \mathrm{C}$, and $-5^{\circ} \mathrm{C}$. The solid fractions were removed from the mixture when the temperature of the mixture reaches each of the pre-determined temperatures; and removing the hexane from the mixture for recovering vitamin $\mathrm{E}$ from the mixture.

The obtained extracted sample was determined for the composition of vitamin $\mathrm{E}$ by analyzing the quantities of its derivatives comprising of total-tocopherol, total-tocotrienol and total-vitamin E using normal-phase HPLC method no. Ce 8-89 (AOCS, 1997).

\subsection{Determination of the Physical Chemical Properties of the Extracted Vitamin E}

The chemical properties of the extracted vitamin E, including iodine value, saponification value, acid value, peroxide value, volatile matter (hexane), iron, copper, lead, arsenic, palmitic acid, oleic acid, and linoleic acid, were determined in Laboratory Center for Food and Agricultural Products. The property of iodine value was tested with method no. Cd 1b-87 (AOCS, 1997) when the tests for properties of saponification value, acid value, and peroxide value were conducted with method no. 920.16, 969.17, 965.33, respectively (AOAC, 2000). Also, the property of volatile matter (hexane) was tested with in house method based on GC-MS with headspace technique, and the properties of iron, copper, lead, arsenic were measured with method no. 999.10 (AOAC, 2000). In addition, the properties of palmitic acid, oleic acid, and linoleic acid were determined with the method no. 996.06 (AOAC, 2000).

\subsection{Determination of Scavenging Activity, Reducing Power and Antioxidant Activity of the Extracted Vitamin E}

\subsubsection{Scavenging Activity on the 2,2-diphenyl-1-picrylhydrazyl (DPPH) Radical}

The extracted vitamin $\mathrm{E}$ was determined for the scavenging activity at concentrations from 1.25 to $700 \mathrm{ppm}$ using the DPPH radical as described by Kim (2005) with modification. A volume of $4 \mathrm{ml}$ of vitamin E fraction was dissolved in the mixture of chloroform and methanol in the ratio of 2:1 (v/v) and added to a solution of $1 \mathrm{ml}$ of 0.2 $\mathrm{mM}$ DPPH radical in methanol. The mixture was allowed to react for $30 \mathrm{~min}$ at room temperature before determining degree of free radical scavenging activity by measuring the absorbance at $517 \mathrm{~nm}$ by a spectrophotometer (PerkinElmer ${ }^{\mathrm{TM}}$, UV WINLAB version 2.85.04, UK). The capability of the scavenger on the DPPH radical was calculated using the following equation.

$$
\% \text { DPPH radical scavenging effect }=\left[\left(\mathrm{A}_{0}-\mathrm{A}_{1} / \mathrm{A}_{0}\right) \times 100\right]
$$

Where,

$\mathrm{A}_{0}=$ the absorbance at $517 \mathrm{~nm}$ of the control sample, in which the sample treated without adding vitamin $\mathrm{E}$ fraction

$\mathrm{A}_{1}=$ the absorbance at $517 \mathrm{~nm}$ of the vitamin E sample 


\subsubsection{Reducing Power}

The reducing powers of the vitamin $\mathrm{E}$ fraction at different concentrations $(0.00,1.25,2.50,5.00,10.00$ and 20.00 ppm) were determined by a method of Kim (2005) with modification. To $0.1 \mathrm{ml}$ of the sample solution, the $0.25 \mathrm{ml}$ of $0.2 \mathrm{M}$ phosphate buffer at $\mathrm{pH} 6.6$ and $0.25 \mathrm{ml}$ of $1 \%$ potassium ferricyanide $\left[\mathrm{K}_{3} \mathrm{Fe}(\mathrm{CN})_{6}\right]$ were mixed and incubated at $50^{\circ} \mathrm{C}$ for $20 \mathrm{~min}$. Then, $0.25 \mathrm{ml}$ of $10 \%$ trichloroacetic acid was added to the mixture, before it was centrifuged for $10 \mathrm{~min}$ at $3,420 \mathrm{rpm}, 25^{\circ} \mathrm{C}$. Next, $0.25 \mathrm{ml}$ of the upper layer of the solution was mixed with $0.25 \mathrm{ml}$ of distilled water and $0.05 \mathrm{ml}$ of $1 \%$ ferric chloride $\left[\mathrm{FeCl}_{3}\right]$. The obtained solution was measured for the absorbance at $700 \mathrm{~nm}$. The high absorbance indicated increasing of the reducing power.

\subsubsection{Antioxidant Activity}

The antioxidant activity was determined by the ferric thiocyanate (FTC) method. The antioxidant activities of the vitamin $\mathrm{E}$ fraction at various concentrations $(0.0,2.5,5.0,10.0$ and $20.0 \mathrm{ppm})$ on the inhibition of linoleic acid peroxidation was assayed by a modified method of $\mathrm{Kim}(2005)$. The $0.25 \mathrm{ml}$ of the vitamin E fraction at different concentrations was mixed with $2.5 \mathrm{ml}$ of $0.02 \mathrm{M}$ linoleic acid emulsion at $\mathrm{pH} 7.0$ and $2 \mathrm{ml}$ of $0.2 \mathrm{M}$ phosphate buffer at $\mathrm{pH}$ 7.0. The linoleic acid emulsion was prepared by mixing $0.2804 \mathrm{~g}$ of linoleic acid, $0.2804 \mathrm{~g}$ of Tween 20 , and $50 \mathrm{ml}$ of phosphate buffer. Then, the mixture was incubated at $37^{\circ} \mathrm{C}$ for 6 days. To $0.1 \mathrm{ml}$ of the reaction mixture at $24 \mathrm{~h}$ intervals, $4.7 \mathrm{ml}$ of $75 \%$ ethanol, $0.1 \mathrm{ml}$ of $30 \%$ ammonium thiocyanate, $0.1 \mathrm{ml}$ of $0.02 \mathrm{M}$ ferrous chloride in $3.5 \% \mathrm{HCl}$ were added. The peroxide value was determined to evaluate the degree of oxidation by measuring the absorbance at $500 \mathrm{~nm}$. The percentage of inhibition of the linoleic acid peroxidation was calculated for each concentration of vitamin $\mathrm{E}$ fraction by using the following equation.

$$
\% \text { Inhibition }=100-\left[\left(\mathrm{A}_{1} / \mathrm{A}_{0}\right) \times 100\right]
$$

Where,

$\mathrm{A}_{0}=$ the absorbance at $500 \mathrm{~nm}$ of the control sample, in which the sample treated without adding vitamin $\mathrm{E}$ fraction

$\mathrm{A}_{1}=$ the absorbance at $500 \mathrm{~nm}$ of the vitamin E sample

\subsubsection{Analysis of the Malonaldehyde}

The thiobarbituric acid (TBA) test was conducted on the final incubation day ( $5^{\text {th }}$ day) based on a method described by Kim (2005) to determine the malonaldehyde formation from linoleic acid peroxidation. The sample was prepared as previously described in the FTC method. To $1.0 \mathrm{ml}$ of sample solution, $2 \mathrm{ml}$ of $20 \%$ trichloroacetic acid and $2 \mathrm{ml}$ of thiobarbituric acid solution were added. The mixture was then boiled and cooled to about $25^{\circ} \mathrm{C}$. After centrifugation of the mixture for $20 \mathrm{~min}$ at $4,000 \mathrm{rpm}, 25^{\circ} \mathrm{C}$, the absorbance of the supernatant was measured at $532 \mathrm{~nm}$.

2.5 Comparison of the Superoxide Radical Scavenging Activity, Antioxidant Activity and Malonaldehyde Inhibitions of the Extracted Vitamin E with the Commercial $\alpha$-tocopherol and the Synthetic Antioxidants

\subsubsection{Superoxide Radical Scavenging Activity}

The superoxide radical scavenging activities of the extracted vitamin E, $\alpha$-tocopherol, BHA, BHT, PG and TBHQ in linoleic acid emulsion were determined based on the method of Kim (2005) with modification. The linoleic acid emulsion was prepared as previously described in the FTC method. The reaction mixture contained $1.2 \mathrm{ml}$ of 0.05 $\mathrm{M}$ sodium carbonate buffer adjusted to $\mathrm{pH} 10.5,0.1 \mathrm{ml}$ of $3 \mathrm{mM}$ xanthine, $0.1 \mathrm{ml}$ of $3 \mathrm{mM}$ ethylenediaminetetraacetic acid disodium salt [EDTA ${ }_{2} \mathrm{Na}$ ], $0.1 \mathrm{ml}$ of $0.15 \%$ bovine serum albumin, $0.1 \mathrm{ml}$ of 0.75 $\mathrm{mM}$ nitroblue tetrazolium chloride (NBT), and $0.1 \mathrm{ml}$ sample solution. After holding at $25^{\circ} \mathrm{C}$ for $10 \mathrm{~min}$, the reaction process was started by adding $6 \mathrm{mU}$ of xanthine oxidase (XOD) and maintained at $25^{\circ} \mathrm{C}$ for another 10 $\min$. Next, the reaction was stopped by adding $0.1 \mathrm{ml}$ of $6 \mathrm{mM} \mathrm{CuCl}_{2}$. The absorbance of the obtained mixture was measured at $560 \mathrm{~nm}$. The inhibition rate was calculated by measuring the amount of the formazan formed from NBT in the presence of superoxide using the following equation.

$$
\% \text { Superoxide radical scavenging activity }=\left[\left(\mathrm{A}_{0}-\mathrm{A}_{1} / \mathrm{A}_{0}\right) \times 100\right]
$$

Where,

$\mathrm{A}_{0}=$ the absorbance at $560 \mathrm{~nm}$ of the control sample, in which the sample treated without adding vitamin $\mathrm{E}$ fraction;

$\mathrm{A}_{1}=$ the absorbance at $560 \mathrm{~nm}$ of the vitamin E sample. 


\subsubsection{Antioxidant Activities}

The antioxidant activity was measured by the FTC method. The antioxidant activities of different concentrations $(0.0,2.5,5.0,10.0$ and $20.0 \mathrm{ppm})$ of the extracted vitamin E were compared to those of the commercial $\alpha$-tocopherol and the synthetic antioxidants by determining the inhibition of linoleic acid peroxidation (Kim, 2005).

\subsubsection{Malonaldehyde Inhibition}

The TBA Test was performed to evaluate the malonaldehyde inhibition. The malonaldehyde inhibitions of different concentrations $(0.0,2.5,5.0,10.0$ and $20.0 \mathrm{ppm})$ of the extracted vitamin E were compared to those of the commercial $\alpha$-tocopherol and the synthetic antioxidants by determining the inhibition of linoleic acid peroxidation (Kim, 2005).

\subsection{Heat and Storage Stabilities}

\subsubsection{Heat Stability}

A volume of $5 \mathrm{ml}$ of the extracted vitamin $\mathrm{E}$ was transferred into a $10 \mathrm{ml}$ vial that was flushed with nitrogen gas before capping. The vial was submerged into the hot silicone oil controlled at $190 \pm 2^{\circ} \mathrm{C}$ for $0,1,2,3,4,5$ and $6 \mathrm{~h}$ (Nystrom et al., 2007). After heating, the sample was immediately cooled and analyzed for the quantities of vitamin E derivatives, total-tocopherol, total-tocotrienol and total-vitamin E by using the normal-phase HPLC.

\subsubsection{Storage Stability}

The studied samples were stored in an incubator controlled at $30 \pm 2^{\circ} \mathrm{C}$ and at $65 \pm 5 \%$ of relative humidity for 120 days (U.S. Department of Health and Human Services, 2003). The quantities of the vitamin E derivatives, total-tocopherol, total-tocotrienol and total-vitamin E were determined each 15 days using the normal-phase HPLC.

\subsection{Experimental Design and Statistical Analysis}

The experiment was carried out in triplicate $(n=3)$ with 2 measurements for each replication and the data was reported as mean \pm standard deviation. The data collected from the experiments was analyzed by using the analysis of variance (ANOVA). The Duncan's New Multiple Range Test (DMRT) was applied to the test significant difference of means at the level of $P \leq 0.05$.

\section{Result and Discussion}

\subsection{Physical Chemical Characterization of the Extracted Vitamin E}

The vitamin E extracted from the PFAD by the sequential cooling method was used to determine the scavenging activity, antioxidant activity and stability. The vitamin E mixture was analyzed to determine the components by using the normal-phrase HPLC. The study found the mixture contained $\alpha-, \beta-, \gamma$ - and $\delta$-tocopherol, $\alpha-, \beta-, \gamma$ - and $\delta$-tocotrienol and total-vitamin $\mathrm{E}$ of 2,509.57, 9.24, 157.85, 6.70, 1,779.92, 3.97, 2,376.38, 818.80 and 7,662.45 $\mathrm{ppm}$, respectively. The ratio of total-tocopherol and total-tocotrienol were approximately $3: 7$. The vitamin $\mathrm{E}$ sample contained an iodine value of $90 \mathrm{~g} / 100 \mathrm{~g}$, saponification value of $189.97 \mathrm{mg} \mathrm{KOH} / \mathrm{g}$, acid value of 206.70 $\mathrm{mg} \mathrm{KOH} / \mathrm{g}$, peroxide value of $0.28 \mathrm{~m} \mathrm{EqO} / \mathrm{kg}$, volatile matter (hexane) $>100 \mathrm{ppm}$, iron of $8.58 \mathrm{mg} / \mathrm{kg}$, copper of $0.56 \mathrm{mg} / \mathrm{kg}$, lead $<0.12 \mathrm{mg} / \mathrm{kg}$ and arsenic of $0.088 \mathrm{mg} / \mathrm{kg}$. The sample also contained some other fatty acids such as palmitic acid, oleic acid and linoleic acid at 11.94, 65.64 and $15.70 \mathrm{~g} / 100 \mathrm{~g}$, respectively.

\subsection{Bioactive Characterization of the Extracted Vitamin $E$}

\subsubsection{Scavenging Activity on the 2,2-diphenyl-1-picrylhydrazyl (DPPH) Radical}

Figure 1 shows that the DPPH scavenging effect increased with the increasing concentration of vitamin $\mathrm{E}$ in the range of $1.25-20.00 \mathrm{ppm}$. The concentration of $20.00 \mathrm{ppm}$ was the lowest concentration providing the highest DPPH scavenging effect of $89.00 \pm 0.69 \%$, which was enough for performing the activity as effective antioxidant.

The scavenging activities of vitamin E extracted from other sources have been reported. The vitamin E extracted from rice bran by the hydrolysis method using $80 \% \mathrm{KOH}$ required the concentration of $160 \mathrm{ppm}$ of vitamin $\mathrm{E}$ to scavenge the DPPH radical which was equal to the DPPH scavenging effect of $95.17 \pm 0.284 \%$ (Kim, 2005). The rice bran vitamin E studied by Kim (2005) contained $\alpha$-tocopherol, $\gamma$-tocopherol, $\alpha$-tocotrienol and $\gamma$-tocotrienol of $68.29,40.05,78.71$ and $98.24 \mathrm{ppm}$, respectively. The concentrations of these four derivatives were lower than those obtained in this study. As a result, a higher concentration of vitamin $\mathrm{E}$ extracted from rice bran was required for the highest DPPH scavenging effect. The DPPH scavenging effect found in this study was also higher than the one reported by Igbal et al. (2008). In addition, Igbal et al. (2008) reported that vitamin E 
extracted from various kinds of wheat bran in Pakistan achieved only $51-79 \%$ of the scavenging activity of the DPPH radical. The reason for the low activity might be because vitamin E extracted from wheat bran contained only 22-26 ppm of tocopherols and 59-74 ppm of tocotrienols.

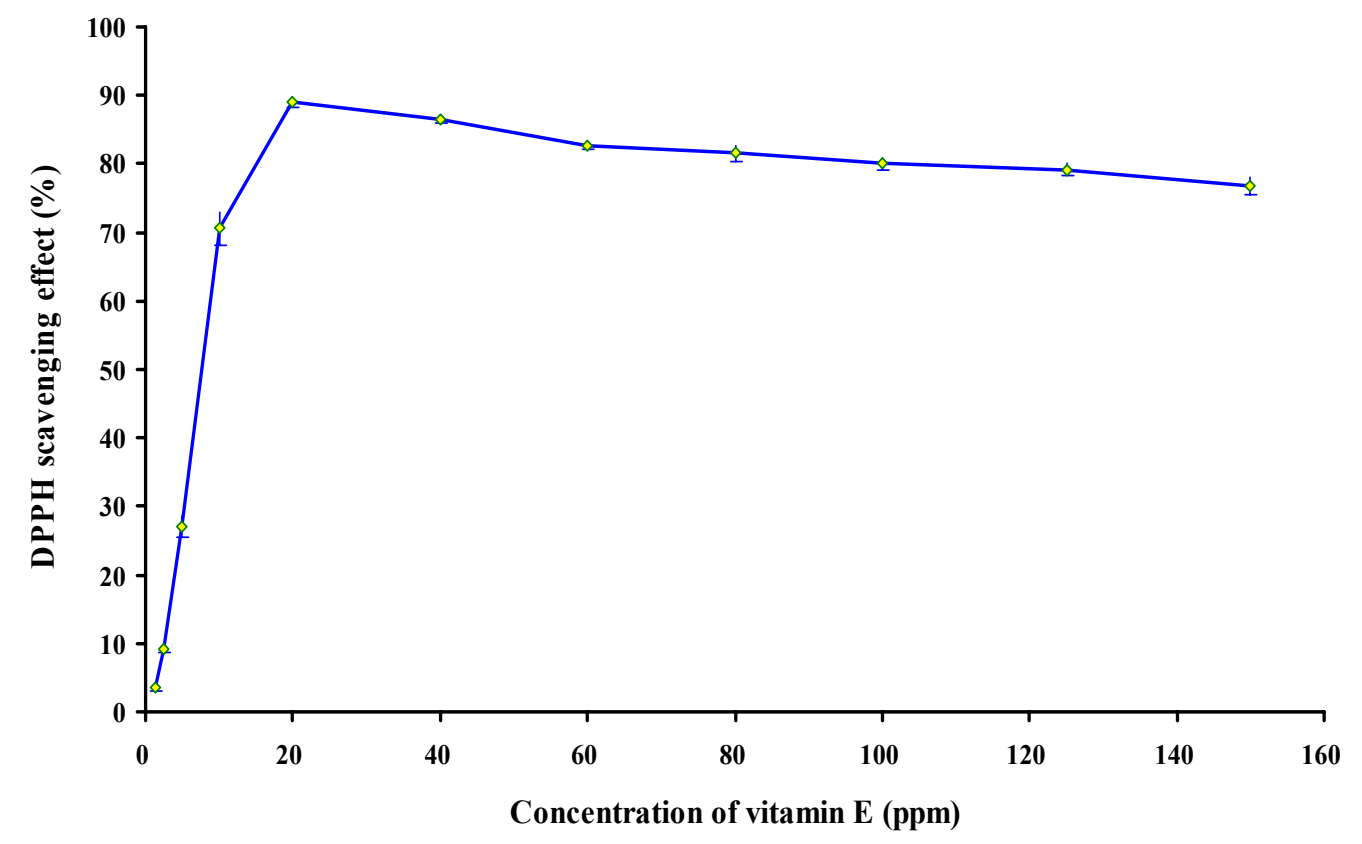

Figure 1. Radical scavenging activity (\%) of vitamin E extracted from PFAD on the DPPH free radicals

\subsubsection{Reducing Power}

The reducing powers were determined by using various concentrations of vitamin $\mathrm{E}$. The reducing powers of vitamin $\mathrm{E}$ significantly increased with increasing vitamin $\mathrm{E}$ concentrations $(P \leq 0.05)$ as shown in Figure 2 . Compared to the study of Kim (2005), the vitamin E extracted from rice bran required the concentration of 160 ppm to provide the equal reducing power to the $20 \mathrm{ppm}$ vitamin $\mathrm{E}$ obtained from this study.

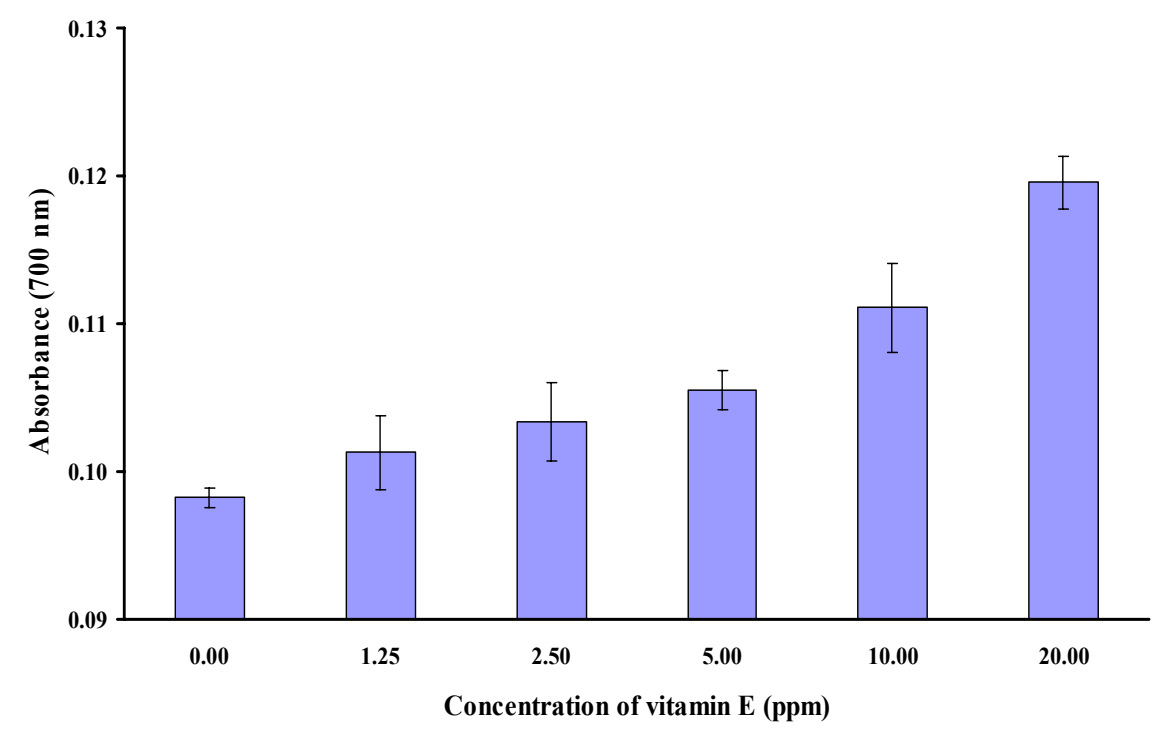


Figure 2. Reducing power (UV absorption at $700 \mathrm{~nm}$ ) of vitamin E extracted from PFAD

\subsubsection{Malonaldehyde Formation from Linoleic Acid Peroxidation}

Figure 3 presents the relationship between the absorbance of the vitamin E samples prepared at various concentrations on the linoleic acid peroxidation during storage. The increasing of the absorbance indicated higher malonaldehyde formation, or the lower inhibition of linoleic acid peroxidation. During the first period of autoxidation of linoleic acid, the peroxide level increased sharply during days 1-5 of storage when vitamin E was not added. After day 5, the peroxide decreased as it changed to malonaldehyde, the secondary oxidation product. The higher the absorbance means, the lower the level of the antioxidant activity. However, the emulsion of linoleic acid added with vitamin E provided lower peroxide than the sample without adding vitamin E. The increasing concentrations of vitamin $\mathrm{E}$ from 2.50 to $20.00 \mathrm{ppm}$ in the emulsion caused slower rate of oxidation of linoleic acid with no statistical significance $(P>0.05)$.

Figure 4 illustrates the relationship of peroxide inhibition of the vitamin $E$ prepared at various concentrations. The peroxide inhibition increased as a result of increasing vitamin $\mathrm{E}$ concentration. The peroxide inhibition sharply increased in 1 day and could inhibit the peroxide formation more than $80 \%$. At day 3 , the highest inhibition was achieved, with $96.94 \pm 0.65,98.33 \pm 0.38,98.42 \pm 0.16$ and $98.79 \pm 0.37 \%$ at the concentrations of $2.50,5.00$, 10.00 and $20.00 \mathrm{ppm}$, respectively. The peroxide inhibition during days 1-3 for each vitamin E concentration was different with statistical significance $(P \leq 0.05)$ while no significant differences $(P>0.05)$ were observed during days 4-6. Nevertheless, vitamin E concentration of only $2.50 \mathrm{ppm}$ was able to inhibit more than $80 \%$ of the peroxide in 1 day.

The correlation between peroxide inhibition and reducing power was found that the reducing power increased when the concentration of vitamin $\mathrm{E}$ increased, which was shown by the increasing UV absorption values at 700 $\mathrm{nm}$ in Figure 2, which resulted in the increasing percentage of peroxide inhibition. The relative coefficient $\left(R^{2}\right)$ between the reducing power and the peroxide inhibition was 0.8099 . This means that the reducing power of the extracted vitamin $\mathrm{E}$ was considerably related to peroxide inhibition.

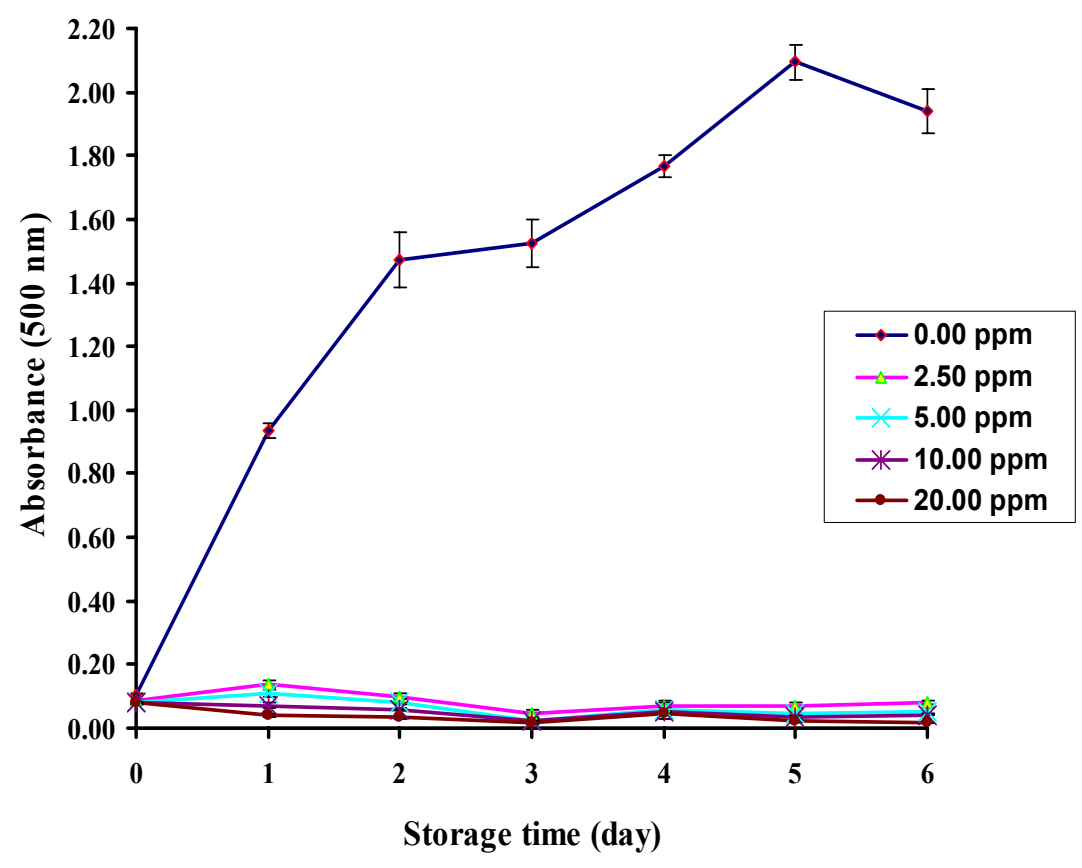

Figure 3. Capability of vitamin E extracted from PFAD to counteract the linoleic acid peroxidation during storage 


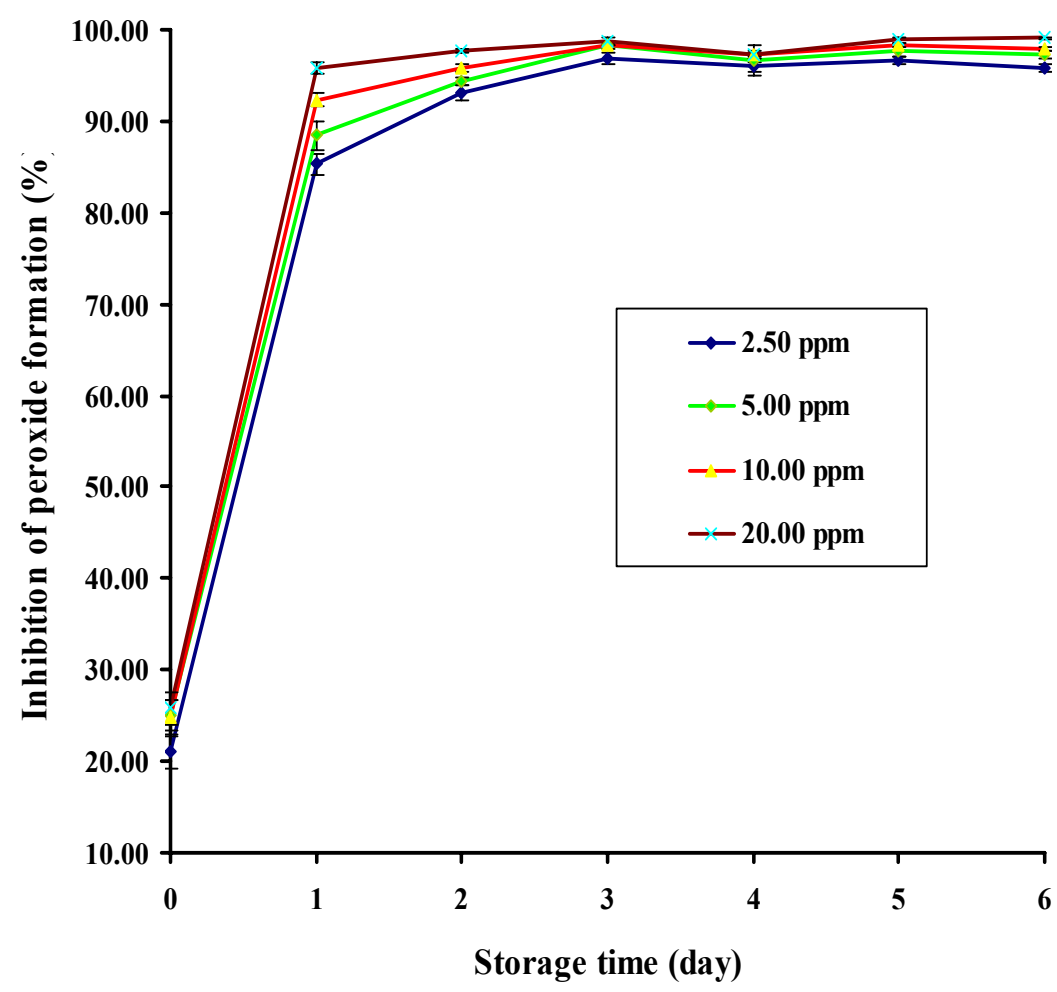

Figure 4. Inhibition of peroxide formation by vitamin E extracted from PFAD at different concentrations under storage conditions

The UV absorption at $532 \mathrm{~nm}$ could refer to malondehyde produced in the oxidation of linoleic acid which contained quite high UV absorption at $532 \mathrm{~nm}$. That means a large amount of malondehyde was produced in the oxidation of linoleic acid and contained a decreasing ability as an antioxidant as shown in Figure 5. The experiment found that the increase in concentration of vitamin $\mathrm{E}$ indicated the decrease in UV absorption. This means that the increase in ability as an antioxidant demonstrated the decrease in quantity of malondehyde. The vitamin $\mathrm{E}$ concentrations of $2.50,5.00,10.00$ and $20.00 \mathrm{ppm}$ contained a high capability in antioxidation or malondehyde inhibition without statistical significance $(P>0.05)$. It was concluded that vitamin E extracted from PFAD at the concentration of $2.50 \mathrm{ppm}$ can inhibit malondehyde similarly to the higher quantity used. Though the use of higher concentration than $2.50 \mathrm{ppm}$ resulted in the decreasing of malondehyde, but it deceased without statistical significance $(P>0.05)$.

According to Kim (2005), vitamin E extracted from rice bran by the hydrolysis method at the concentrations of $2.50,10.00,40.00$ and $160.00 \mathrm{ppm}$ provided the UV absorption at $532 \mathrm{~nm}$ of $0.225,0.175,0.155$ and 0.050 , respectively. While the vitamin E extracted from PFAD in this study at the concentrations of $2.50,5.00,10.00$ and $20.00 \mathrm{ppm}$ provided the UV absorption with no statistical significance $(P>0.05)$ as shown in Figure 5. Therefore, it could be concluded that vitamin E extracted from PFAD at the concentration of $2.50 \mathrm{ppm}$ was able to inhibit the malonaldehyde reaction similarly to vitamin $\mathrm{E}$ from rice bran at the concentration of $160.00 \mathrm{ppm}$.

3.2.4 Comparison of the Superoxide Radical Scavenging Activity, Antioxidant Activity and Malonaldehyde Inhibitions of the Extracted Vitamin E with the Commercial $\alpha$-tocopherol and the Synthetic Antioxidants

\subsubsection{Superoxide Radical Scavenging Activity}

The superoxide radical scavenging property of the extracted vitamin $\mathrm{E}$ was compared to those of the commercial $\alpha$-tocopherol, BHA, BHT, THBQ and PG at the concentration of $20 \mathrm{ppm}$. Figure 6 presents that the superoxide radical scavenging properties of the test sample varied with a statistical significance $(P \leq 0.05)$. In general, the extracted vitamin $\mathrm{E}$ possessed high superoxide radical scavenging property and was similar to those of the TBHQ, BHA and BHT. The high superoxide radical scavenging property could be due to the fact that the 
vitamin E from PFAD contained as high as $65 \%$ tocotrienols, especially $\gamma$ - and $\alpha$-tocotrienol. The pronounced inhibiting of superoxide radical of the tocotrienols has been reported (Kim, 2005).

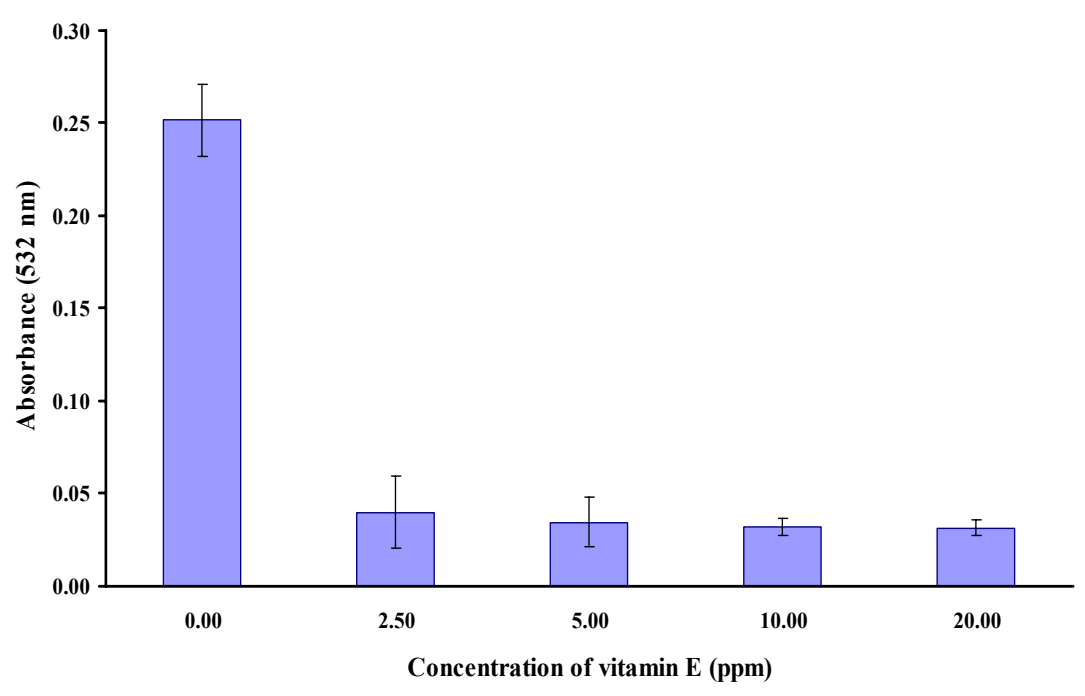

Figure 5. Absorbance of the extracted vitamin E obtained from the thiobarbituric acid method

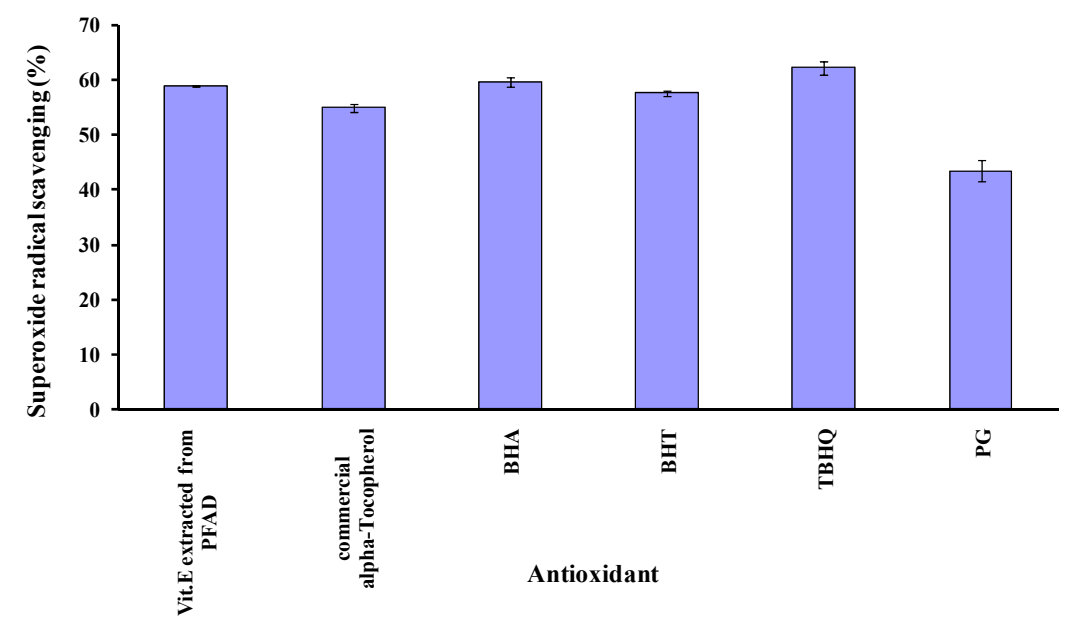

Figure 6. Superoxide radical scavenging activities of the extracted vitamin E from PFAD in comparison to others antioxidants

\subsubsection{Antioxidant Activity}

The result of UV absorption at $500 \mathrm{~nm}$ showed the peroxide measured by ferricthiocyanate (Figure 7). If the UV absorption at $500 \mathrm{~nm}$ was low, it referred to a high antioxidative property. The experiment found that peroxide, in the first period of autioxidation of linoleic acid emulsion without the addition of vitamin E from PFAD and synthetic antioxidants, sharply increased during days 1-5 of storage. As for the sample of linoleic with vitamin E added from PFAD and synthetic antioxidants, it provided a different peroxide quantity with statistical significance $(P \leq 0.05)$ during days $1-2$. However, during days $3-6$, it provided a different quantity of peroxide with no statistical significance $(P>0.05)$ as linoleic acid system with vitamin $\mathrm{E}$ added and synthetic antioxidants provided low peroxide.

At the concentration of $20.00 \mathrm{ppm}$, the result of antioxidant property revealed that the TBHQ contained the highest antioxidant potential, while BHA, BHT, extracted vitamin E, commercial $\alpha$-tocopherol and PG contained slightly less activity, respectively (Figure 8). From Figure 9, the antioxidant activity of the 20.00 ppm extracted 
vitamin E was higher than those of the commercial $\alpha$-tocopherol and PG $(P>0.05)$. Low UV absorption at 532 $\mathrm{nm}$ referred to a high ability to inhibit malonaldehyde formation. The antioxidants containing high to low malonaldehyde inhibition were the BHA, TBHQ, BHT, the extracted vitamin E, the commercial $\alpha$-tocopherol, and PG, respectively. The concentration of malonaldehyde in each sample was compared to that obtained from the ferric thiocyanate method to find the relation of the two experiments. Vitamin E from the PFAD contained more intensity in inhibiting linoleic acid oxidation than the commercial $\alpha$-tocopherol and PG but provided lower ability in inhibiting linoleic acid oxidation than those of the TBHQ, BHA, and BHT. This discrepancy may result from higher tocotrienols in the extracted vitamin $\mathrm{E}$ or the synergistic effect of tocopherols and tocotrienols. The tocopherols and tocotrienols were able to interfere in radical chain reaction effectively by providing phenolic hydrogen and lipid peroxy radical. However, the antioxidant activity of tocopherols and tocotrienols may be the difference in food and organism (Kim, 2005).

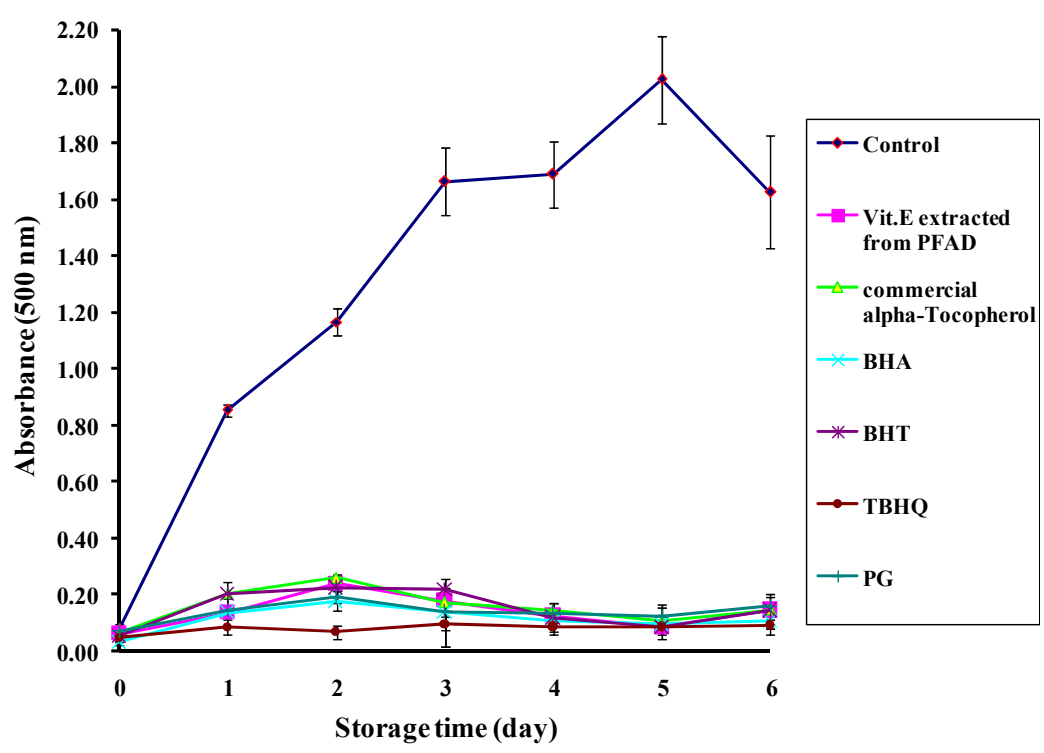

Figure 7. Absorbance of the extracted vitamin E and the other antioxidants on the linoleic acid emulsion peroxidation

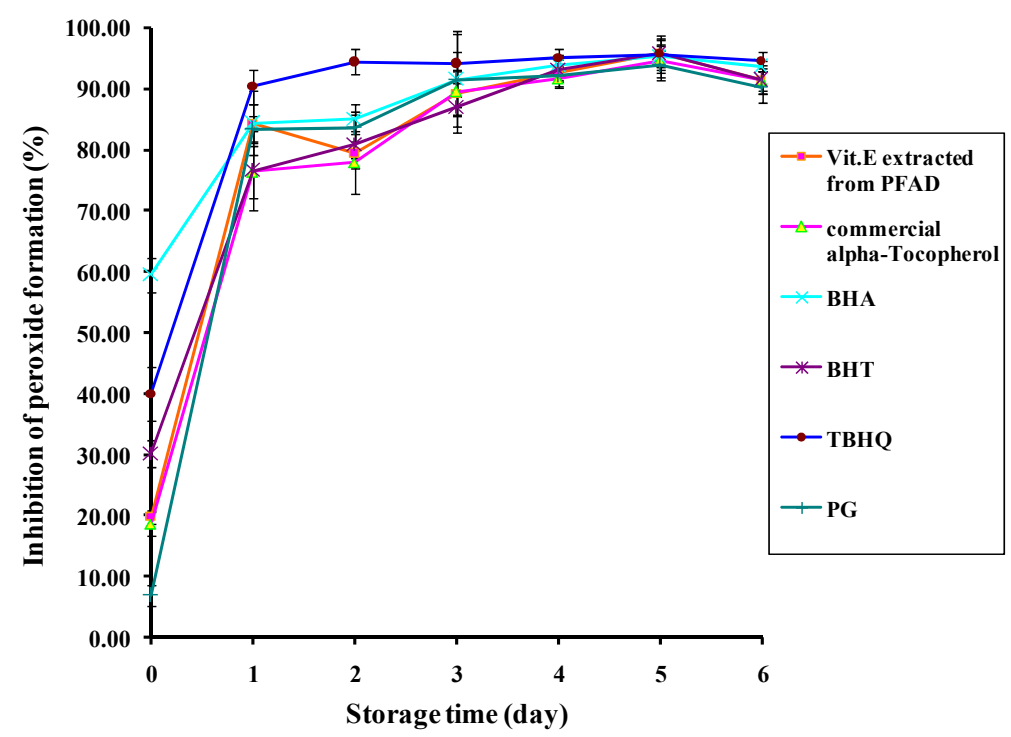

Figure 8. Peroxide inhibitions of the extracted vitamin E and the other antioxidants 


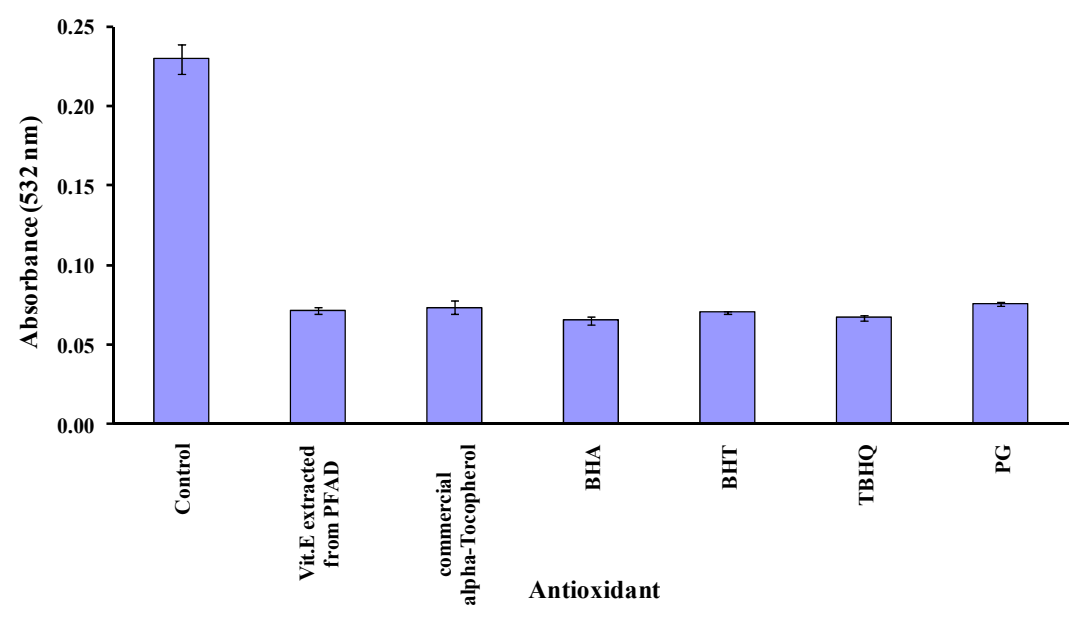

Figure 9. Absorbance of the extracted vitamin $\mathrm{E}$ and the other antioxidants obtained from the thiobarbituric acid method

\subsubsection{Heat and Storage Stabilities}

\subsubsection{Heat Stability}

The heat stabilities at $190^{\circ} \mathrm{C}$ during $1,2,3,4,5$ and $6 \mathrm{~h}$ of vitamin $\mathrm{E}$ derivatives, total-tocopherol, total-tocotrienol and total-vitamin E extracted from PFAD were shown in Figure 10. In the consideration of the reducing of the vitamin $\mathrm{E}$ derivatives after heating at $190^{\circ} \mathrm{C}$ for $3 \mathrm{~h}$, the decreasing concentration of $\alpha-, \beta-, \gamma-$, $\delta$-tocopherol and $\alpha$-, $\beta$-, $\gamma$-, $\delta$-tocotrienol were $91.59,73.31,94.95,50.08,64.85,53.15,52.88$ and $79.35 \%$, respectively. Thus, it could be concluded that most of the vitamin $\mathrm{E}$ derivatives remained more than $50 \%$ of its initial content. However, the concentrations of vitamin $\mathrm{E}$ derivatives, total-tocopherol, total-tocotrienol and total-vitamin E significantly decreased $(P \leq 0.05)$ when heating at $190^{\circ} \mathrm{C}$ for $6 \mathrm{~h}$. The concentrations of $\alpha-, \beta-, \gamma-$, $\delta$-tocopherol, $\alpha-, \beta-, \gamma-, \delta$-tocotrienol, total-tocopherol, total-tocotrienol and total-vitamin E decreased by 51.54 , $48.19,91.01,0.00,43.04,27.27,0.00,66.13,51.01,41.11$ and $44.52 \%$, respectively.

Regarding the initial concentrations before heating of the total-tocopherol, total-tocotrienol and total-vitamin E, they were 2,657.24, 5,057.39 and 7,714.63 ppm, respectively. After heating for $6 \mathrm{~h}$, the concentrations changed to $1,355.41 \mathrm{ppm}(51.01 \%), 2,078.85 \mathrm{ppm}(41.11 \%)$ and 3,434.26 ppm (44.52\%), respectively. This result indicated that the concentration percentages of total-tocotrienol were less than those of the total-vitamin $\mathrm{E}$ and total-tocopherol, respectively. That means tocotrienols possessed less stability during heating at $190^{\circ} \mathrm{C}$ for $6 \mathrm{~h}$ than the tocopherols, resulting to less quantity and a decreased concentration of total-vitamin E. In addition, the rate of reducing of total-tocopherol $(0.47 \% / \mathrm{h})$ was less than that of the total-tocotrienol $(0.56 \% / \mathrm{h})$. This finding agreed with the study of Eitenmiller and Lee (2004) who conducted the research of vitamin E in olein palm oil in simulation frying system at 176 and $185^{\circ} \mathrm{C}$ for $6 \mathrm{~h}$ and discovered that $\alpha$-tocopherol was more stable than $\delta$-, $\alpha$ and $\gamma$-tocotrienol.

Overall, the extracted vitamin $\mathrm{E}$ was stable at $190^{\circ} \mathrm{C}$ for about $3 \mathrm{~h}$ when concentrations of vitamin $\mathrm{E}$ derivatives decreased by less than $50 \%$ of initial concentrations. At this temperature, it was widely used in frying food processing with addition of vitamin $\mathrm{E}$ an antioxidant. However, it was suggested that more vitamin $\mathrm{E}$ should be added into frying oil after frying for around $3 \mathrm{~h}$ together with considering acid value of the oil, as the index indicating free fatty acid generated in frying oil, because free fatty acid affected the vitamin E stability (Rossi et al., 2007). 


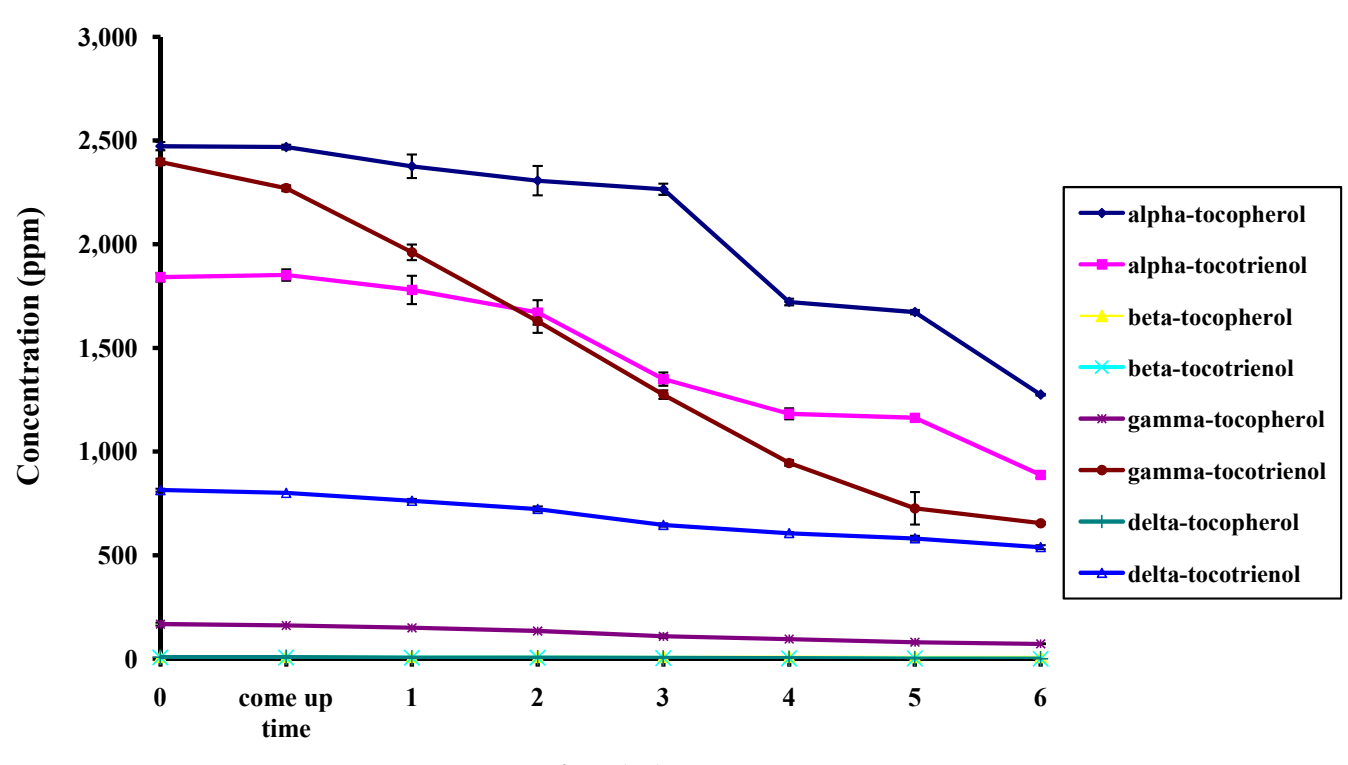

Time (hr)

Figure 10. Changes of the concentrations of the vitamin $\mathrm{E}$ derivatives during heating at $190^{\circ} \mathrm{C}$

\subsubsection{Storage Stability}

The extracted vitamin $\mathrm{E}$ was stored at $30^{\circ} \mathrm{C}$ for 120 days and analyzed for the concentrations of vitamin $\mathrm{E}$ derivatives, total-tocopherol, total-tocotrienol and total-vitamin $\mathrm{E}$ every 15 days of storage. The results were shown in Figure 11. The concentrations of vitamin $\mathrm{E}$ derivatives, total-tocopherol, total-tocotrienol and total-vitamin E significantly decreased $(P \leq 0.05)$ during storage. The concentration percentages of $\alpha-, \beta-, \gamma-$, $\delta$-tocopherol, $\alpha-, \beta-, \gamma$-, $\delta$-tocotrienol, total-tocopherol, total-tocotrienol and total-vitamin $\mathrm{E}$ decreased to 79.13 , $85.30,95.16,79.75,98.16,91.26,88.49,95.94,80.45,90.02$ and 86.68 , respectively. The initial concentrations of total-tocopherol, total-tocotrienol and total-vitamin E were 2,666.53, 4,967.67 and 7,634.20 ppm, respectively. After storing for 120 days, they were 2,142.85 (80.45\%), 4,465.53 (90.02\%) and 6,608.38 ppm (86.68\%), respectively. The result showed that total-tocotrienol contained higher concentration than total-tocopherol, which means that tocotrienols possessed more stability during 120 days of storage than tocopherols.

The decreasing concentrations of the vitamin E derivatives during storage showed that the changes in quantities of vitamin E derivatives decreased with the storage time and the decreasing rate was different depending on the characteristics of those derivatives. Tocopherols showed the higher decreasing rate than the tocotrienols. The decreasing rate of tocopherols and tocotrienols during storage were 0.16 and $0.09 \%$ /day, respectively. 


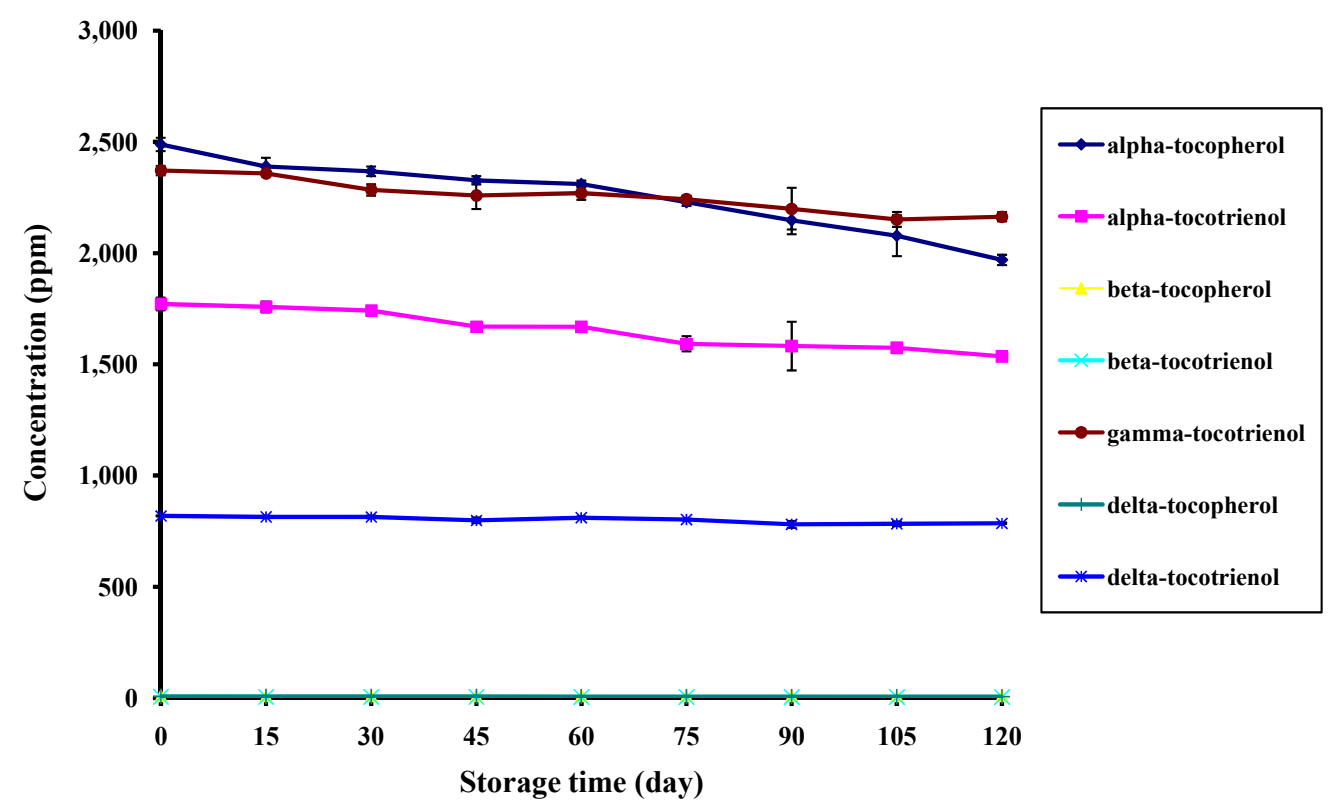

Figure 11. Changes of vitamin E derivatives during storage

\section{Conclusion}

The study of properties of the vitamin E extracted from PFAD by the sequential cooling hexane confirmed the effective ability of the extracted vitamin $\mathrm{E}$ to inhibit the formation of radicals, peroxide generated during lipid oxidation, which could be applied in biological and food system. The concentration of the extracted vitamin E mixture at $20 \mathrm{ppm}$ expressed the maximum DPPH scavenging effect of $89 \%$. According to the methods of reducing power and ferric thiocyanate, the extracted vitamin E mixture at the concentration of $2.5 \mathrm{ppm}$ could inhibit the oxidation of linoleic more than $80 \%$ within 1 day. The superoxide scavenging activity of the extracted vitamin E mixture was greater than those of the BHT, synthetic $\alpha$-tocopherol, and PG, respectively. The total antioxidant activity of the extracted vitamin E was similar to those of the BHT and commercial $\alpha$-tocopherol. The total-vitamin E remained about $73.35 \%$ after heating at $190^{\circ} \mathrm{C}$ for $3 \mathrm{~h}$ and most of the vitamin $\mathrm{E}$ derivatives were reduced less than $50 \%$. The tocopherol derivatives were more heat-stable than the tocotrienol derivatives while $\gamma$-tocopherol was the most heat-stable derivative. The concentration of total-vitamin $\mathrm{E}$ stored at $30^{\circ} \mathrm{C}$ for 120 days remained about $87 \%$.

\section{Acknowledgements}

We would like to express our gratitude to The Thailand Research Fund for the financial support. We wish to thank Chumporn Palm Oil Industry Public Company Limited for supporting the PFAD.

\section{References}

AOAC. (2000). Official Methods of Analysis of AOAC international (17th ed.). AOAC international. Maryland. USA.

AOCS. (1997). Official methods and recommended Practice (5th ed.). Champaign, Illinois: American Oil Chemists' Society (Method Ce 8-89).

Chu, B. S., Baharin, B. S., \& Quek, S. Y. (2002). Factors affecting pre-concentration of tocopherols and tocotrienols from palm fatty acid distillate by lipase-catalysed hydrolysis. Journal of Food Chemistry, 79, 55-59. http://dx.doi.org/10.1016/S0308-8146(02)00177-2

Eitenmiller, R. R., \& Landen, O. (1999). Vitamin Analysis for the Health and Food Sciences. New York, USA: CRC Press Inc. http://dx.doi.org/10.1201/9780203970140

Eitenmiller, R. R., \& Lee, J. (2004). Vitamin E: Food chemistry, composition, and analysis. New York: Marcel Dekker, Inc. 
Evans, C. J., Kodali, R. D., \& Addis, B. P. (2002). Optimal tocopherol concentrations to inhibit soybean oil oxidation. Journal of the American Oil Chemists' Society, 79, 47-51. http://dx.doi.org/10.1007/s11746-002-0433-6

Gapor, M. T., Hasamudin, W., Hassan, W., \& Sulong, M. (2002). Phytochemicals for Nutraceuticals from the By-product of Palm Oil Refining. Retrieved 7 October, 2004, from http://palmoilis.mpob.gov.my/webbased/pod36_13-19.pdf

Gianello, R., Libinaki, R., Azzi, A., Gavin, P. D., Negis, Y., Zingg, J. M., ... Ogru, E. (2005). $\alpha$-Tocopheryl phosphate: a novel, natural form of vitamin E. Journal of the Society for Free Radical Biology and Medicine, 39, 970-976. http://dx.doi.org/10.1016/j.freeradbiomed.2005.05.016

Goh, S. H., Choo, Y. M., \& Ong, S. H. (1985). Minor constituent of palm oil. Journal of the American Oil Chemists' Society, 62(20), 237-240. http://dx.doi.org/10.1007/BF02541384

Hunt, T. K., Jeromin, L., Johannisbauer, W., Bernhard, G., Wogatzki, H., \& Wood, J. D. (2000). Recovery of tocopherols. European Patent, EP 0992 499. Cited by B. S. Chu, B. S. Baharin, \& S. Y. Quek (2002). Factors affecting pre-concentration of tocopherols and tocotrienols from palm fatty acid distillate by lipase-catalysed hydrolysis. Journal of Food Chemistry, 79, 55-59. Retrieved from http://www.sciencedirect.com/science/article/pii/S0308814602001772

Iqbal, S., Sultana, B., \& Anwar, F. (2008). Effect of different cooking methods on the antioxidant activity of some vegetables from Pakistan. Journal of Food Science and Technology, 43, 560-567. http://dx.doi.org/10.1111/j.1365-2621.2006.01504.x

Jung, Y. M., \& Min, B. D. (1990). Effects of $\alpha-$, g-, and d-tocopherols on oxidative stability of soybean oil. Journal of Food Science, 55(5), 1464-1465. http://dx.doi.org/10.1111/j.1365-2621.1990.tb03960.x

Kim, S. J. (2005). Radical scavenging capacity and antioxidant activity of the E vitamer fraction in rice bran. Journal of Food Science, 70(3), 208-213. http://dx.doi.org/10.1111/j.1365-2621.2005.tb07127.x

Knekt, P., Aromaa, A., Maatela, J., Aran, R. K., Nikkari, T., \& Hakama, M. (1992). Serum vitamin E and risk of cancer, among Finnish men during a 10-year follow up. American Journal of Epidemiology, 127, 28-41. Retrieved from http://aje.oxfordjournals.org/content/127/1/28.short

Leong, W. L. (1992). The Refining and Fractionation of Palm Oil. Palm Oil Mill Engineers-Executives Training Course 14th Semester 1. PORIM Bangi. 1-6.

Maydani, M. (1995). Fat-soluble vitamins -Vitamin E. The Lancet, 345, 170-175.

Nesaretnam, K., Yew, W. W., Wahid, M. B. (2007). Tocotrienols and cancer: Beyond antioxidant activity. European Journal of Lipid Science and Technology, 109(4), 445-452. http://dx.doi.org/10.1002/ejlt.200600212

Ng, W. K., Wang, Y., Ketchimenin, P., \& Yuen, K. H. (2004). Replacement of dietary fish oil with palm fatty acid distillate elevates tocopherol and tocotrienol concentrations and increases oxidative stability in the muscle of African catfish, Clarias gariepinus. Journal of Aquaculture, 233, 423-437. http://dx.doi.org/10.1016/j.aquaculture.2003.10.013

Nystrom, L., Tanja, A., Lampi, A.-M., Moreau, R. A., \& Piironen, V. (2007). A comparison of the antioxidant properties of steryl ferulates with tocopherol at high temperatures. Journal of Food Chemistry, 101, 947-954. http://dx.doi.org/10.1016/j.foodchem.2006.02.046

Qureshi, A. A., Ong, A. S. H., Gapor, M. T., Witt, G. de, \& Chong, Y. H. (1988). Suppression of Cholesterol Biosynthesis and Hypocholesterolemic Effects of tocotrienols from Palm Oil in the Chicken Model. Paper presented at The National Oil Palm/Palm Oil Conference: Current Development, 11-15 October, 1988, Shangri-La Hotel. Kuala Lumpur. Cited by W. H. Leong, C. T. Chuah, \& H. David. The Nutritional Properties of Palm Tocotrienols - A Unique \& Novel Vitamin E. Retrieved from http://palmoilis.mpob.gov.my/ webbased/pod36_13-19.pdf

Qureshi, A. A., Pearce, B. C., Rosnah, M. N., Gapor, M. T., Peterson, D. M., \& Elson, C. E. (1996). Dietary $\alpha$-Tocopherol Attenuates the Impact of g-Tocotrienol on Hepatic 3-Hydroxy-3-Methylglutaryl Coenzyme A Reductase Activity in Chickens. Journal of American Institute of Nutrition, 389-394. Cited by W. H. Leong, C. T. Chuah, \& H. David. The Nutritional Properties of Palm Tocotrienols - A Unique \& Novel Vitamin E. Retrieved from http://palmoilis.mpob.gov.my/ webbased /pod36_13-19.pdf 
Qureshi, A. A., Qureshi, N., Wright, J. J., Shen, Z., Kramer, G., Gapor, M. T., ... Bradlow, B. A. (1991). Lowering of Serum Cholesterol in Hypercholesterolemic Humans by Tocotrienols (PALMVITEE). The American Journal of Clinical Nutrition, 52, 1021S-1026S. Cited by W. H. Leong, C. T. Chuah, \& H. David. The Nutritional Properties of Palm Tocotrienols - A Unique \& Novel Vitamin E. Retrieved from http://palmoilis.mpob.gov .my/webbased/pod36_13-19.pdf

Rossi, M., Alamprese, C., \& Ratti, S. (2007). Tocopherols and tocotrienols as free radical-scavengers in refined vegetable oils and their stability during deep-fat frying. Journal of Food Chemistry, 102, 812-817. http://dx.doi.org/10.1016/j.foodchem.2006.06.016

Sanagi, M. M., See, H. H., Ibrahim, W. A. W., \& Naim, A. A. (2005). Determination of carotene, tocopherols and tocotrienols in residue oil from palm pressed fiber using pressurized liquid extraction-normal phase liquid chromatography. Analytica Chimica Acta, 538(1-2), 71-76. http://dx.doi.org/10.1016/j.aca.2005.02.028

Top, A. G. (1990). Content of vitamin E in palm oil and its antioxidant activity. Journal of Palm Oil Development, $12,25-27$.

U.S. Department of Health and Human Services, Food and Drug Administration, Center for Drug Evaluation and Research (CDER) and Center for Biologics Evaluation and Research (CBER). (2003). Guidance for Industry Q1A(R2) Stability Testing of New Drug Substances and Products. ICH. 